\title{
Um inferno para ser visto: 0 Apocalipse de Pedro e os sofrimentos físicos dos condenados
}

\author{
Hell to be seen: the Apocalypse of Peter and the \\ physical sufferings of the damned
}

\section{Un infierno para ser visto: el Apocalipsis de Pedro y los sufrimientos físicos de los condenados}

\author{
Carlos Eduardo Mattos*
}

\begin{abstract}
RESUMO
O Apocalipse de Pedro é conhecido por ser um dos textos mais antigos da tradição apócrifa a tratar do tema do Além-Mundo cristão. É considerado também o mais plástico dos apocalipses apócrifos. Plástico porque é no Apocalipse de Pedro que os sofrimentos físicos dos condenados ao Inferno são expostos ao visionário de maneira mais corpórea, ampla e significativa. Os pecados são punidos e expostos em torturas detalhadas. São apresentados, cena a cena, homens e mulheres que cometeram pecados sexuais como adultério, fornicação, aborto, relações sexuais consideradas inadequadas. Este artigo tem como objetivo descrever brevemente esses castigos e os condenados a cada um deles; levantar hipóteses sobre o que teria motivado narrativas como essas no Cristianismo Primitivo (CP) e defender que, essa característica plástica do ApPe é proposital, no sentido de que, ao receber essas narrativas, de forma oral ou mesmo, posteriormente, de forma escrita, os interlocutores deveriam, pelo ato de leitura, imaginar, visualizar essas cenas descritas de maneiras absolutamente grotescas. Palavras-chave: Cristianismo Primitivo; grotesco; Inferno; apocalipse; apócrifo.
\end{abstract}

\begin{abstract}
The Apocalypse of Peter is known to be one of the oldest texts in the apocryphal tradition dealing with the theme of the Christian After-World. It is also considered the most plastic of the apocryphal apocalypses. Plastic because it is in the Apocalypse of Peter that the physical sufferings of those condemned to Hell are exposed to the visionary in a more corporeal, broad and meaningful way. Sins are punished and exposed in detailed torture. Scene by scene, men and women who have committed sexual sins such as adultery, fornication, abortion, sexual relations considered inappropriate are presented. This article aims to briefly describe these punishments and those sentenced to each of them; to raise hypotheses about what would have motivated narratives like these in Early Christianity and to defend that, this plastic characteristic of ApPe is purposeful, in the sense that, when receiving these narratives, orally, in written form, the interlocutors should, by the act of reading, imagin, visualiz these scenes described in absolutely grotesque ways.

Keywords: Early Christianity; grotesque; Hell; apocalypse; apocrypha.
\end{abstract}

* Doutorando em Ciências da Religião no PPGCdR da Universidade Metodista de São Paulo. Bolsista CAPES. E-mail: edubadofe@yahoo.com.br 


\begin{abstract}
RESUMEN
Se sabe que el Apocalipsis de Pedro es uno de los textos más antiguos de la tradición apócrifa que trata el tema más allá del mundo cristiano. También se considera el más plástico de los apocalipsis apócrifos. Plástico porque es en el Apocalipsis de Pedro que los sufrimientos físicos de los condenados al Infierno están expuestos al visionario de una manera corpórea, amplia y significativa. Los pecados son castigados y expuestos en torturas detalladas. Escena por escena, se presentan hombres y mujeres que han cometido pecados sexuales como adulterio, fornicación, abortos, relaciones sexuales consideradas inapropiadas. Este artículo tiene como objetivo describir brevemente estos castigos y los condenados a cada uno de ellos; para plantear hipótesis sobre lo que habría motivado narrativas como estas en el cristianismo primitivo y defender eso, esta característica plástica de ApPe es útil, en el sentido de que, al recibir estas narraciones, oralmente o incluso más tarde, en forma escrita, los interlocutores deberían, por el acto de leer, imaginar, visualizar estas escenas descritas de manera absolutamente grotesca.

Palabras clave: Cristianismo Primitivo; grotesco; Infierno; apocalipses; apócrifos.
\end{abstract}

\title{
Introdução
}

Neste artigo propomos uma visita ao Inferno. Guiados pela fonte do Apocalipse de Pedro, imaginaremos as cenas de condenados sendo torturados por suas práticas e teremos uma experiência sensorial: em alguns momentos, acharemos graça, em outros, repulsa pelo texto nos fazer deparar com fluidos corporais como excrementos e sangue. Começaremos conhecendo melhor a fonte em suas versões e as hipóteses sobre suas composições e transmissão, suas origens e sua característica visual, ou seja, um texto que precisa ser imaginado. Isso feito, ingressaremos na fonte propriamente dita; no entanto, precisaremos de um auxílio teórico para melhor compreendê-la. Quem nos auxiliará nessa tarefa é Mikhail Bakhtin e sua teoria sobre o realismo grotesco. Por fim, tentaremos entender porque o Cristianismo Primitivo criou narrativas que descrevem o Inferno e suas penas, imagens que se tornaram tão populares.

Inicialmente abordaremos as diferentes versões e as origens da obra em questão, o Apocalipse de Pedro.

\section{O Apocalipse de Pedro: debates iniciais sobre as diferentes versões}

O Apocalipse de Pedro (ApPe de agora em diante) é, segundo Martha Himmelfarb, o texto mais antigo do Cristianismo em que se encontra uma descrição do Inferno. Segundo ela, algumas citações de Clemente de Alexandria localizam essa obra em meados do segundo século. Antes da descoberta, em 1887, de um manuscrito grego do oitavo ou nono século na caverna de um monge em Akhmin, no Alto Egito, o ApPe era conhecido apenas por alusões e menções em listas canônicas (HIMMELFARB, 1983, p. 9). Na primeira década do século XX uma longa versão etíope surgiu numa coleção 
de manuscritos. Há uma discussão, inicialmente sustentada por M R James, na qual a versão etíope era mais próxima do original do que a versão grega. James sugere que a versão grega do ApPe foi adaptada para servir como parte do Evangelho de Pedro, outro texto descoberto no mesmo códex da caverna em Akhmin. Ele acredita que a versão etíope tenha sido traduzida mais diretamente (HIMMELFARB, 1983, p. 11). Além disso, apenas a versão etíope oferece o texto de forma completa. A versão grega é mais fragmentada (SCHEELMELCHER, 2003, p. 623).

Alguns textos de Pais da Igreja mencionam o ApPe, e essas menções são importantes para destacarmos o papel exercido pela obra e em algum aspecto, fortalecer os argumentos de sua datação antiga. Citando apenas algumas das obras que mencionam o ApPe temos: o fragmento de Muratori $;^{1}$ Clemente de Alexandria nas obras Hypotoposes e Eclogae Propheticae cita o ApPe por volta do ano 200; o Catalogus Claromontanus, um catálogo oriental das Escrituras Sagradas do século III que elenca o ApPe; Eusébio em sua História Eclesiástica, cerca do ano 339, menciona a obra junto com o Pastor de Hermas, para citar alguns dos mais antigos (LECH, 2005, p. 326).

A despeito desse debate, Himmelfarb aponta elementos da apocalíptica judaica presentes nas descrições do Inferno cristãs primitivas: Ela observou que uma pergunta de um visionário levado ao Além, nessas descidas aos infernos é seguida por uma explicação demonstrativa de um guia sobrenatural. Essa característica formal distintiva deve ter se desenvolvido a partir dos apocalipses de jornada cósmica ao Além, das quais a mais antiga é a jornada de Enoque no Livro dos Vigilantes. Esses recursos, segundo Himmelfarb, localizam o ApPe na tradição apocalíptica judaica. Embora admitindo que Himmelfarb observa corretamente que as viagens ao Inferno se desenvolveram dentro da tradição apocalíptica judaica, Jan Bremmer também enfatiza que algumas das punições têm precedentes claros nas descrições gregas e romanas do Hades. Por outro lado, Lech aponta que, no seu caráter geral, o ApPe tem a particularidade de, ao invés do interesse na pessoa do Redentor, enfatizar o aspecto da situação da vida após a morte. Seus paralelos sobre imaginários de recompensas e castigos que esperam as pessoas depois da morte, encontram-se em crenças gregas presentes em passagens do final da República de Platão, como, por exemplo, a Visão de Er (LECH, 2005, p. 331). Além disso, como nos apocalipses, no Hades grego as punições ocorrem agora e não numa fase posterior da história. Essa, defende Bremmer, é provavelmente uma visão

\footnotetext{
O Fragmento de Muratori é uma lista de escritos sagrados, primeiro publicado por Muratori em 1740, encontrado por ele em um manuscrito do séc VII ou VIII na Biblioteca Ambrosiana em Milão, datado no séc III ou IV.
} 
minoritária entre os judeus até o século II (BREMMER, 2003, p. 7). Ou seja, não é necessário para esses relatos, que se espere um julgamento final para que os condenados sofram suas penas.

Colocadas essas questões iniciais, a seguir explanaremos alguns aspectos que, segundo Bremmer, são característicos da literatura grega sobre o Além-Mundo e estão presentes no ApPe.

\section{Precedentes gregos das descrições do Além-Mundo}

Bremmer postula que o mundo grego antigo tem no livro VI da Eneida de Virgílio uma descrição importante do Além-Mundo, composto de julgamentos morais, banquetes maravilhosos e uma vida após a morte no paraíso. É possível encontrar em autores diferentes, como Plutarco e Apuleio, já nos primeiros anos da era cristã, descrições de uma continuidade da vida após a morte. Nesse contexto deve-se compreender o ApPe. Bremmer enumera elementos tipicamente gregos no texto do ApPe: correntes de fogo, chafurdar na lama, almas de pessoas assassinadas observando seus assassinos e condenados que se jogam do alto de uma ladeira e ao cair, são reconduzidos ao alto de novo, por seus torturadores. Nesses castigos que se repetem, Bremmer reconhece uma familiaridade com os mitos gregos de Íxion e Sísifo².

Além disso, Bremmer aponta a utilização de nomes gregos para anjos que interagem com Pedro em sua jornada ao Inferno nos versos 13 (anjo Tartarouchos) e 8 (anjo Temelouchos). Esses anjos aparecem também no Apocalipse de Paulo e nos apocalipses de Maria e de Baruque, assim como em versões de feitiços dos Papiros Mágicos Gregos. Esses anjos trazem um tridente na mão, fazendo referência com a descrição do deus grego Poseidon. Outro aspecto que o autor defende como característica grega no ApPe é a menção ao Lago Acherusa e aos Campos Elíseos, conhecidos temas do Além-Mundo grego, embora, em Homero, o Lago Acherusa se localize no norte de Thesprotia e os Campos Elíseos nos confins da Terra. Ou seja, o ApPe menciona a geografia do além do mundo grego, mas modifica essa geografia, de acordo com seus próprios interesses. (BREMMER, 2003, p 10)

Em conclusão, Bremmer concorda com Himmelfarb sobre as heranças da apocalíptica judaica do ApPe, embora observe muitos elementos do orfismo e das narrativas gregas a respeito do submundo. Com isso, ele afirma

\footnotetext{
Íxion foi condenado por enganar os deuses, na mitologia, a ficar preso em uma roda gigante ardendo em chamas e Sísifo ao morrer, foi enviado ao Inferno, onde rolava uma pedra enorme por um dia inteiro para o alto de uma montanha. Ao final do dia, a pedra rolava sobre ele e no dia seguinte, ele precisava recomeçar o trabalho.
} 
ser ainda mais provável determinar a localização do ApPe no Egito, entre judeus da diáspora, em Alexandria, como a pesquisa geralmente também localiza. Ainda sobre a discussão a respeito das origens, Scheelmelcher aposta na tese de uma dupla origem da apocalíptica judaica e dos Oráculos Sibilinos do judaísmo helênico. (SCHEELMELCHER,2003, p 543)

Essa discussão serve ao propósito único de lançar alguma luz sobre origens dessa literatura. De fato, o que importa é observar o quanto tais escritos foram importantes na formação do imaginário religioso do Cristianismo Primitivo, enquanto prática de religião popular nos primeiros séculos da era cristã. A seguir, discutiremos um dos aspectos mais relevantes da apocalíptica cristã: seu caráter visual.

\section{A importância da perspectiva visual para o Cristianismo Primitivo}

Assim como no caso da profecia, a apocalíptica também apresenta suas revelações em forma de mensagem, especialmente por meio de visões. Nos textos apocalípticos essa característica da visão é ainda mais forte. Paulo Nogueira defende que o Cristianismo Primitivo nasce a partir dos relatos de visões de mulheres camponesas da Galileia. A partir de Marcos 16.1-5, o autor apresenta a característica do medo e do temor, que o evangelho atribui àquelas mulheres, como vocabulário indicativo de uma epifania. $\mathrm{O}$ fato de o Cristo ter sido motivo de uma experiência visionária por seus seguidores após a ressurreição ressignificou o movimento de Jesus (NOGUEIRA, 2005, p. 13-42).

De fato, Nogueira acredita que Jesus se torna o Cristo a partir dos relatos de visões a respeito dele após a ressurreição, esses camponeses visionários e o fato mudam toda a perspectiva do que será construído como dogma a partir de então. Essa primeira experiência visionária é paradigmática para muitas outras que serão fundamentais para a construção e seguimento do CP. O relato do primeiro martírio (Estevão em At 6.8-7.60), a vocação de Saulo em At 9. 1-19 e o Apocalipse de João são exemplos de novas visões do ressuscitado presentes no NT que marcam o CP e possibilitam rapidamente ao Cristianismo o conjunto de narrativas, crenças e práticas que o transformam em religião distinta de sua matriz judaica. Esse processo ocorre, curiosamente, com os seguidores de Jesus vinculados à mística visionária judaica: nas contemplações judaicas do trono de Deus, sua corte e seu culto nos céus, os cristãos desenvolvem uma imagem complexa do Cristo inserido nesse cenário (NOGUEIRA, 2005, p. 15-16) 


\section{Apocalipses para serem vistos}

A marca essencial da literatura apocalíptica é a perspectiva visionária. Desde as cenas da obra que dá nome a todo o gênero, o Apocalipse de João, em que o visionário inicia sua seção de visões com o Trono de Deus e em seguida vê uma série de destruições, encerrando-se com a visão da nova Jerusalém, passando pela apocalíptica judaica, com os nomes de figuras importantes tendo visões dos palácios celestiais na Merkavah; O Mito dos Vigilantes e toda a trajetória dos textos apocalípticos e os Hodayot nos Manuscritos do Mar Mor$t 0^{3}$, o fator marcante entre toda essa extensa literatura é a percepção visual: um personagem importante tem uma experiência em que vê a revelação de um mistério. Seja nos palácios celestiais, seja na Nova Jerusalém, diante do Trono de Deus, seja no Além-Mundo, a revelação do mistério divino dá-se por meio da visão. Nesse sentido, o ApPe apresenta um diferencial importante: Pedro vê os mortos condenados ao Inferno. Vê as condenações e os detalhes de seus castigos, com certo requinte de crueldade, além de aspectos repugnantes. A seguir, selecionamos um trecho da obra:

\section{Trecho do Apocalipse de Pedro e postulados}

21. Mas vi também um outro lugar, no lado oposto deste, muito sombrio; este era o lugar da punição. E aqueles que lá estavam sendo punidos, e os anjos que os puniam, usavam vestes escuras, de acordo com o ar daquele lugar.

22. Lá, alguns estavam pendurados pelas suas línguas: eram aqueles que tinham blasfemado contra o caminho da justiça; e foi colocado fogo debaixo deles que os abrasava e atormentava.

23. E vi um grande lago de lodo ardente no qual estavam enfiadas certas pessoas que tinham se desviado da justiça e anjos atormentadores estavam colocados sobre elas.

24. E haviam também outras, mulheres penduradas pelo seu cabelo, em cima daquele lodo fervente: estas eram as que se adornavam para o adultério; mas os homens que se uniram com elas na corrupção do adultério (estavam pendurados) pelos pés e tinham suas cabeças naquele lodo e gritavam (em voz alta): "Não acreditávamos que chegaríamos até este lugar!"

25. E eu vi os assassinos e seus cúmplices lançados num vale cheio de répteis venenosos e atormentados por estas bestas e assim contorcendo-se nesta tortura; e vermes os afligiam como nuvens escuras. Mas as almas dos assassinados estavam lá e olhavam o castigo daqueles assassinos e diziam: "Ó Deus, justo é teu julgamento!"

26. E perto daquele lugar vi outro vale para o qual corriam o fluxo e os excrementos daqueles que estavam sendo castigados e se tornaram num lago. E lá estavam sentadas mulheres com os excrementos até seus pescoços e na frente delas estavam sentadas muitas crianças, chorando, que foram por elas, abortadas. E das crianças saiam raios de fogo e golpeavam as mulheres nos olhos. Eram estas que conceberam filhos fora do casamento e procuraram aborto.

Para maior detalhamento, ver: NOGUEIRA, 2005, p. 23-28 
27. E outros homens e mulheres estavam em chamas até a cintura e foram lançados num lugar escuro e golpeados por espíritos maus e suas entranhas foram comidas por vermes insaciáveis: eram aqueles que perseguiram os justos e os entregaram.

28. E perto deles havia novamente mulheres e homens que roíam seus lábios e estavam em tormentos, com ferros em brasa nos seus olhos. Eram aqueles que blasfemaram e caluniaram o caminho da justiça.

29. E na frente deles estavam ainda outros homens e mulheres que roíam suas línguas e tinham fogo abrasador nas suas bocas. Eram as falsas testemunhas.

30. E num outro lugar havia pedras em brasa, mais afiadas que espadas ou qualquer faca, e mulheres e homens em trapos imundos rolavam nelas, em tormento. Eram os ricos que confiaram nas suas riquezas e não tiveram piedade dos órfãos e das viúvas e menosprezaram os mandamentos de Deus.

31. E num outro grande lago, cheio de piche e sangue e lodo que borbulhava, estavam homens e mulheres mergulhados até os joelhos: eram os usurários e os que cobraram juros sobre juros.

32. E outros homens e mulheres que estavam sendo lançados num grande precipício abaixo, chegavam ao fundo e eram levados a subir novamente do precipício por aqueles que estavam colocados sobre eles, e novamente eram lançados para baixo e não tinham descanso deste castigo. Eram aqueles que macularam seus corpos agindo como mulheres; e as mulheres que estavam com eles eram aquelas que se deitaram uma com a outra, como um homem com uma mulher.

33. E junto àquele precipício havia um lugar cheio de muito fogo e lá estavam homens que fizeram para si, com suas próprias mãos, imagens talhadas em lugar de Deus. E junto a esses estavam outros homens e mulheres com varas, golpeando uns aos outros, nunca cessando de tal castigo.

34. E outros novamente perto deles, mulheres e homens, queimando e se virando e assando: eram aqueles que abandonaram o caminho de Deus. ${ }^{4}$

O texto destacado acima é correspondente a uma seção da obra, destinado ao relato de descrição dos castigos dos condenados no Inferno, do texto de Akhmin. Lech defende que se trata de um texto muito judaico na severidade de sua moralidade e em sua fraseologia, no sentido do uso frequente das palavras "justo" e "justiça”, assim como pela ideia de que Deus, e não Cristo, virá julgar os pecadores. O autor compreende, ainda, paralelos ao texto do ApPe na segunda carta de Pedro, além de Is 66.24:

Eles sairão e verão os cadáveres dos homens que prevaricaram contra mim; porque o seu verme nunca morrerá, nem o seu fogo se apagará; e eles serão um horror para toda a carne. ${ }^{5}$

\section{E Mc 9. 44:}

[onde não lhes morre o verme, nem o fogo se apaga.]

\footnotetext{
4 Tradução da versão em inglês em SCHEELMELCHER, 2003, p. 628-632.

5 Todas as citações bíblicas são da Bíblia de Estudo Almeida. Revista e Atualizada.
} 
E a parábola do Rico e Lázaro, em Lucas 16. 19ss. Sobre o relato de Lucas, trataremos mais tarde.

Inicialmente, o ApPe parece ser uma nova narrativa sobre o discurso de Jesus acerca do fim dos tempos, proferido no monte das Oliveiras, em Mc 13, junto com a transfiguração de Jesus em Mc 9.2-8, expandidos pela inclusão da descrição de lugares de castigo e a transfiguração ampliada pela visão do paraíso. O final da versão etíope mostra que não se trata de uma ampliação, uma vez que, depois da transfiguração, Jesus não desce do Monte com os discípulos, mas ascende ao segundo céu, junto com Elias e Moisés.

Distanciando-se dos paralelos canônicos e se aproximando da literatura grega, o ApPe utiliza imagens das religiões de mistério e da literatura grega. Não estamos no Sheol judaico, mas no meio das torturas do Tártaro e da lama fervente do Lago Acherusa, como descreve Platão na República.

A seguir, para continuar aprofundando os temas do ApPe, trataremos da análise dos pecados e dos castigos descritos na obra à luz da teoria do grotesco de Mikhail Bakhtin. Daremos, portanto, um salto epistemológico.

\section{Análise do ApPe à luz do grotesco em M. Bakhtin}

Mikhail Bakhtin escreveu nos anos de 1930 seus célebres ensaios sobre a teoria do romance. Em sua obra, A Cultura Popular na Idade Média e no Renascimento, encontramos algumas definições do conceito de grotesco. Segundo Bakhtin, o estilo grotesco é marcado pelo exagero, o hiperbolismo, o excesso. No grotesco, assiste-se à ridicularização de certos fenômenos sociais, levando esses exageros ao extremo. Esse exagero causa uma espécie de satisfação de ver realizado um desejo impossível sobre determinada situação social. Nele, o exagero toca a monstruosidade. No grotesco, o objeto transpõe os seus limites, deixa de ser ele mesmo (BAKHTIN, 2010, p. 275). Ao tratar do conceito de grotesco, Bakhtin discute longamente sobre a importância do corpo.

No estilo grotesco, a descrição do corpo é fundamental. Esse tema é essencial para tratarmos do ApPe e das descrições de corpos de condenados castigados no Inferno. O corpo grotesco é um corpo em movimento, nunca acabado, sempre em estado de criação. Para Bakhtin, os órgãos que conectam o corpo com o exterior, que fazem o movimento de saída do corpo, e, por isso, são os limites da relação do corpo com o exterior e com outros corpos são os mais destacados no grotesco: órgãos sexuais, ventre, nariz, boca e nádegas. São sempre esses os membros em destaque no corpo grotesco. Isso retoma a atenção para o nosso relato apocalíptico: os pecadores são punidos no Inferno, por meio dos seus órgãos sexuais, além da presença dos pecados 
sexuais. Ao lado destes, estão também os pecados de fala: fofoca, maledicência, blasfêmia, falso testemunho. Novamente, foco em outro dos órgãos do corpo grotesco: a boca. É interessante o destaque à boca e aos pecados chamados "de fala" (fofoca, falso testemunho), uma vez que aproximam o tema à função atribuída por Bakhtin ao grotesco.

Para Bakhtin, o corpo grotesco fundamentalmente serve a duas funções: o riso e a injúria (BAKHTIN, 2010, p. 278). As funções e atribuições do corpo grotesco em nossa fonte (ApPe) veremos a seguir.

\section{O Inferno do ApPe como espaço de inversão e corpos grotescos}

O ApPe apresenta uma imagem distorcida de todo o corpo: cabeças são mergulhadas na lama (possivelmente um eufemismo para fezes); mulheres são penduradas pelos cabelos, olhos e bocas são queimados, pessoas roem suas próprias línguas, enquanto outras são penduradas por elas, homens são pendurados pelos pés (provável eufemismo para órgãos sexuais), ricos pulam e dançam sobre pedras afiadas em brasa. Todas essas cenas estão em contraste com a beleza, a pureza e a santidade descritas nas imagens do lugar reservado aos santos, no Céu. Essa inversão é apresentada, segundo aponta István Czachesz (2003, p. 114), na apresentação dos corpos pendurados de cabeça para baixo. O Inferno é um mundo em que a existência humana continua, de forma invertida. Essa lógica pode ser ainda observada nos castigos dos ricos, que dançam sobre pedras pontiagudas em brasas. Esse castigo subverte o imaginário do Além-Mundo grego em que os ricos são descritos dançando em simpósios e festas, fazendo com que eles, no Inferno do ApPe, vestidos de trapos, dancem animados por espíritos maus que investem contra eles.

Além disso, a lógica de inversão também pode ser observada na já mencionada história que Jesus conta aos discípulos sobre um homem rico e um mendigo chamado Lázaro, em Lc 16.19ss. Segundo essa narrativa, um homem tão rico que fazia banquetes todos os dias e se vestia com muito luxo tinha em sua porta um mendigo cujas feridas eram lambidas por cães, chamado Lázaro. Os dois morrem e, no Além, há uma inversão imediata: o mendigo Lázaro vai para o seio de Abraão, onde recebe refrigérios de seus sofrimentos, enquanto o rico passa a sofrer no Hades, de tal forma que clama por uma gota de água para se refrescar. Rafael de Campos observa similaridades e uma relação de intertextualidade ${ }^{6}$ dessa narrativa canônica com um texto muito popular do mundo antigo grego, o Diálogo dos Mortos,

6 Para Daniel Marguerat, intertextualidade é uma relação de copresença entre dois ou vários textos ou como presença efetiva de um texto dentro de outro (2009, p. 130). 
de Luciano de Samósata (CAMPOS, 2015, p. 111). Nessa obra, a personagem principal, o filósofo cínico Menipo, ao chegar ao Hades se surpreende e ironiza a presença de figuras ilustres de sua época pelo estado deplorável e cadavérico que a morte lhes confere (LUCIANO, 2007). Para Czachesz, o escrito de Luciano não tem pretensões de pregar preceitos morais, enquanto Lucas e o ApPe marcam qualidades morais a partir dos valores judaicos e cristãos (CZACHESZ, 2003, p. 16).

Outra marca do grotesco no ApPe são os fluidos corporais. Em muitas cenas os condenados são descritos sentados, ajoelhados ou imersos em sangue, suor, pus e excrementos. Bakhtin compreende que os órgãos de limite do corpo e seus produtos (fluidos corporais) são temas marcantes e presentes do grotesco que geram o nojo, o risível e, em especial, a injúria.

$\mathrm{Na}$ parte final deste artigo, abordaremos algumas hipóteses levantadas pela pesquisa a respeito do ApPe, propondo avaliar as razões pelas quais o CP teria optado por narrar o Além-Mundo tão peculiarmente, criando cenas e formando imaginários grotescos sobre o futuro daqueles que considera pecadores.

\section{Por que descrever o Inferno? Algumas hipóteses}

Além das reações mais comuns ao ler narrativas como a do ApPe (em alguns casos, o riso, em outros, certa repulsa, ou até os dois ao mesmo tempo), o contato com obras como esse apocalipse pode gerar questionamentos sobre as razões que levaram o CP a produzir tal literatura. Alguns dos pesquisadores já mencionados neste artigo, como Czachesz e Himmelfarb, apostam em algumas hipóteses para explicar essa motivação.

Czachesz aposta, inicialmente, numa aproximação das penas dos condenados ao Inferno com a Lei de Talião, mencionado em parte no livro do Êxodo, no capítulo 21: "Olho por olho, dente por dente", mas ele mesmo reconhece a fragilidade do argumento, uma vez que essa correspondência só é plenamente verificável nos casos de perseguidores do Cristianismo sendo queimados, dos assassinos que são torturados sob as vistas de suas vítimas e das mães que recebem raios nos olhos de seus bebês abortados. Contra-argumentando, ele mesmo apresenta uma vertente ainda mais radical. $\mathrm{Na}$ passagem do Sermão da Montanha, lemos:

Se o teu olho direito te faz pecar, arranca-o e atira-o para longe de ti; pois te é melhor que se perca um dos teus membros do que seja todo o teu corpo lançado no inferno. E, se a tua mão direita te faz pecar, corta-a e atira-a para longe de ti; porque te é melhor que um dos seus membros se perca do que seja todo o teu corpo lançado no inferno (Mt 5.29-30). 
Czachesz defende que na Torá membros do corpo devem ser punidos pelos pecados cometidos e que no Sermão da Montanha há, de certa forma, uma radicalização disso. É possível encontrar no ApPe essa correspondência entre membros que conduziram ao crime e o castigo punindo o corpo todo por causa desse membro.

Outra hipótese levantada por Czachesz sobre as motivações de descrições grotescas de torturas no Inferno diz respeito às descrições de castigos no mundo inferior dos apocalipses cristãos, elas refletem os sofrimentos dos mártires cristãos e as torturas aplicadas pelas autoridades romanas em geral. Fontes greco-romanas de tortura são relativamente parcas. A razão provavelmente é a aversão estética à descrição de sofrimento físico, o que também explica a ausência de tais detalhes em textos mitológicos. No sistema legal, a tortura era aplicada principalmente aos escravos cujos testemunhos não fossem aceitos. A tortura de cidadãos livres era restrita. Cidadãos romanos, com a exceção de crimem malestattis (pena por algum crime), não eram torturados até Marco Aurélio (160-180 d.C.). A tortura era utilizada fora do quadro legal como instrumento de terror ditatorial (CZACHESZ, 2014, p. 32).

$\mathrm{O}$ autor se utiliza de Atas dos Mártires como referencial sobre o uso da tortura contra os cristãos pelas autoridades romanas, mas defende que, mesmo que tenha havido perseguição sob Domiciano, não existem menções de torturas. Portanto, se o Apocalipse de Pedro foi escrito na primeira metade do segundo século este fato não demonstra que as descrições de Inferno refletiram o sofrimento dos mártires. Embora as figuras de perseguidores, adoradores de ídolos e blasfemadores apareçam no Inferno do ApPe, os castigos aplicados a esses pecadores não podem ser tipicamente associados com a experiência das perseguições. Isso exclui, portanto, esta hipótese e mesmo a anterior, de que as descrições façam referência direta à Lei de Talião.

Caso observemos bem, os pecados descritos no ApPe são de natureza moral, em sua maioria: falso testemunho, blasfêmia, fofoca, injúrias (pecados verbais) e adultério, fornicação, práticas homossexuais e aborto (pecados sexuais). Himmelfarb observa que, surpreendentemente, eles estão em evidência e se destacam na comparação com outros pecados vistos como centrais na tradição bíblica. Por exemplo, assassinato e roubo aparecem poucas vezes como pecados nos relatos de viagens ao Inferno, ainda que sejam proibidos no Decálogo tão claramente quanto adultério, blasfêmia e dar falso testemunho (HIMMELFARB, 1983, p. 73).

Pode ser que o forte interesse por pecados sexuais e verbais nas descrições de Inferno seja por tratar-se de pecados invisíveis. Fofoca e calúnia são ocorrências diárias, impenetráveis para a legislação. Quão menores sejam os 
grupos sociais, mais intensos tais pecados provavelmente serão. Pecados sexuais também são, quase por definição, privados, precisamente os pecados que nunca vêm à frente no tribunal. Assassinato é difícil de esconder, e o assassino quase sempre é trazido à justiça perante a corte. Mas para ver caluniadores e adúlteros colherem a recompensa justa por seus crimes escondidos será preciso aguardar o castigo no Além, após a morte (HIMMELFARB, 1983, p. 73).

Nossa hipótese para explicar tais narrativas é a de que os cristãos primitivos utilizaram essas imagens como retórica para, de certa forma, "vingar" ou fazer justiça a algumas práticas com as quais eles discordavam. Além da impossibilidade de ver tais pecadores alcançados pela lei humana, havia no $\mathrm{CP}$, a nosso ver, um forte desejo de ver práticas discordantes serem punidas, ainda que essa fosse uma possibilidade reservada apenas para o futuro. Ao mesmo tempo, seguiam o padrão apocalíptico de retórica de uma imagética e de violência nas descrições. Ao se deparar com tais narrativas, os interlocutores precisavam interagir com os sentidos: imaginar as fortes cenas, quase sentir os terríveis odores do fogo e dos fluidos corporais e também as dores descritas pelas torturas sofridas no Inferno para não se aproximarem das práticas inadequadas e ao mesmo tempo, saber que seus praticantes encontrariam seus destinos no Além.

Nesse aspecto da violência retórica que resulta na decomposições de corpos dos condenados em torturas eternas no Inferno, encontramos o elo de ligação com a teoria de grotesco de Bakhtin: os corpos expostos às torturas são dissecados, com suas partes baixas expostas, penduradas, imersas em excrementos. Essas cenas grotescas desenhadas pela narrativa operam o efeito imaginativo-visual nos interlocutores da época e faz parte da nossa hipótese. A narrativa tem por intuito encenar o sofrimento dos condenados, com seus corpos sendo torturados dessa maneira grotesca. Ler tais castigos e sofrimentos deve criar essas imagens nas mentes dos leitores: imaginar, cena a cena, cada tortura narrada pelo texto.

\section{À maneira de conclusão}

Descrever visões ou viagens ao Além-Mundo, especialmente ao Inferno e as penas sofridas pelos condenados ali encerrados se tornou parte importante do movimento cristão nos primeiros séculos. Muitos relatos surgiram ao longo dos primeiros séculos do Cristianismo com essa mesma característica. Sempre um visionário, geralmente um personagem famoso como Felipe, Tomé, Pedro, Paulo, Maria, é escolhido para ver as maravilhas desfrutadas pelos santos no Céu e, em seguida, testemunhar as penas sofridas pelos 
condenados ao Inferno. Essa jornada é guiada por um anjo ou, no caso do ApPe, pelo próprio Cristo. O Apocalipse de Pedro além de ser considerado o relato mais antigo em que está presente uma descrição do Inferno é também um dos textos mais plásticos, ou seja, em que o sofrimento físico e corpóreo dos condenados é mais plenamente explorado.

De fato, o ApPe não é o apocalipse mais popular e influente como o Apocalipse de Paulo ou Visio Pauli, que inspirou a obra medieval de Dante Alighieri, A Divina Comédia. Mas pesquisadores como Martha Himmelfarb e István Czachesz acreditam que mesmo o Apocalipse de Paulo tem elementos de intertextualidade com o ApPe. E isso só fortalece nosso argumento acerca do apelo popular que estes textos tiveram e sua forte circulação dentro do Cristianismo Primitivo, influenciando as práticas e as narrativas cristãs. Paulo Nogueira defende que tais narrativas exageradas são experimentos de mundo dos primeiros cristãos, testando mundos hipotéticos, subvertendo hierarquias e lógicas (NOGUEIRA, 2018, p. 113).

Nossa hipótese é que, ao subverter essas lógicas e hierarquias, os cristãos primitivos criaram recursos retóricos para responder e, de certa forma, fazer justiça às práticas com as quais não concordavam por meio dessas obras ficcionais.

\section{Referências bibliográficas}

BAKHTIN, Mikhail. A cultura popular na Idade Média e no Renascimento: o contexto de François Rabelais. São Paulo: Hucitec, 2010.

BIBLIA DE ESTUDO ALMEIDA. Barueri: Sociedade Bíblica do Brasil, 2006.

BREMMER, Jan; CZACHESZ, István (org). The Apocalypse of Peter. Leuen: Peeters Press, 2003.

CAMPOS, Rafael. O homem rico e Lázaro: as relações invertidas no Hades. São Paulo: Reflexão, 2015.

CZACHESZ, István. The grotesque body in Early Christian discourse: Hell, scatology and metamorphosis. New York: Routledge, 2014.

EMERSON, Caryl; MORSON, Gary Soul. Mikhail Bakhtin: criação de uma prosaística. São Paulo: Edusp, 2008.

HIMMELFARB, Martha. Tours of Hell: an Apocalyptic form in Jewish and Christian literature. Philadelphia: Fortress Press, 1983.

LUCIANO. Diálogo dos Mortos. Trad e org de Henrique G. Muracho. São Paulo: Edusp, 2007.

MARGUERAT, Daniel; BOURQUIN, Yvan. Para ler as narrativas bíblicas: iniciação à análise narrativa. São Paulo: Loyola, 2009. 
NOGUEIRA, Paulo A. de S. Religião de visionários: o Cristianismo Primitivo relido a partir de sua experiência fundante. In: NOGUEIRA, Paulo A. de S. (org). Religião de visionários: a apocalíptica e misticismo no Cristianismo Primitivo. São Paulo: Loyola, 2005.

NOGUEIRA, Paulo A. de S. Narrativa e cultura popular no Cristianismo Primitivo. São Paulo: Paulus, 2018.

SCHEELMELCHER, Wilhelm. New Testament Apocrypha. Writings Relating to the Aposttles Apocalypses and Related Subjects. Vol. 2. Louisville: Westminster John Knox Press, 2003.

Submetido em: 27-2-2020

Aceito em: 27-4-2020 